\title{
Results of Active Middle Ear Implantation in Patients With Mixed Hearing Loss After Middle Ear Surgery: A Prospective Multicenter Study (the ROMEO Study)
}

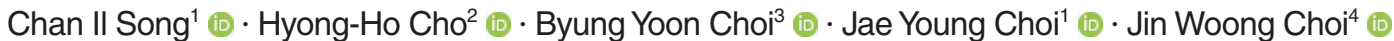

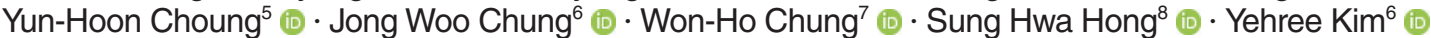

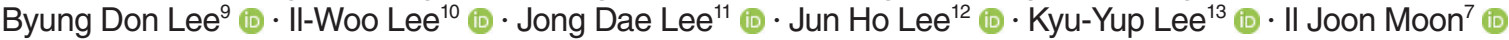

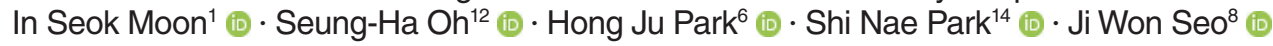

\begin{abstract}
${ }^{1}$ Department of Otorhinolaryngology, Yonsei University College of Medicine, Seoul; ${ }^{2}$ Department of Otolaryngology-Head and Neck Surgery, Chonnam National University Hospital, Chonnam National University Medical School, Gwangju; ${ }^{3}$ Department of Otorhinolaryngology, Seoul National University Bundang Hospital, Seoul National University College of Medicine, Seongnam; ${ }^{4}$ Department of Otorhinolaryngology-Head and Neck Surgery, Chungnam National University School of Medicine, Daejeon; ${ }^{5}$ Department of Otolaryngology, Ajou University School of Medicine, Suwon, ${ }^{6}$ Department of Otorhinolaryngology-Head and Neck Surgery, Asan Medical Center, University of Ulsan College of Medicine, Seoul; ' ${ }^{7}$ epartment of Otorhinolaryngology-Head and Neck Surgery, Samsung Medical Center, Sungkyunkwan University School of Medicine, Seoul; ${ }^{8}$ Department of Otorhinolaryngology-Head and Neck Surgery, Samsung Changwon Hospital, Sungkyunkwan University School of Medicine, Changwon; ${ }^{9}$ Department of Otorhinolaryngology-Head and Neck Surgery, Soonchunhyang University College of Medicine, Seoul; ${ }^{10}$ Department of Otorhinolaryngology-Head and Neck Surgery, Pusan National University Yangsan Hospital, Pusan National University School of Medicine, Yangsan; ${ }^{11}$ Department of Otorhinolaryngology-Head and Neck Surgery, Soonchunhyang University Bucheon Hospital, Soonchunhyang University College of Medicine, Bucheon; ${ }^{12}$ Department of Otorhinolaryngology-Head and Neck Surgery, Seoul National University Hospital, Seoul National University College of Medicine, Seoul; ${ }^{13}$ Department of Otorhinolaryngology-Head and Neck Surgery, Kyungpook National University Hospital, School of Medicine, Kyungpook National University, Daegu; ${ }^{14}$ Department of Otorhinolaryngology-Head and Neck Surgery, College of Medicine, The Catholic University of Korea, Seoul, Korea
\end{abstract}

Objectives. This study was conducted to evaluate the user satisfaction, efficacy, and safety of round window (RW) vibroplasty using the Vibrant Soundbridge (VSB) in patients with persistent mixed hearing loss after mastoidectomy.

Methods. The study included 27 patients (mean age, 58.7 years; age range, 28-76 years; 11 men and 16 women) with mixed hearing loss after mastoidectomy from 15 tertiary referral centers in Korea. The VSB was implanted at the RW. The Korean translation of the Abbreviated Profile of Hearing Aid Benefit (APHAB) questionnaire and the Korean version of the International Outcome Inventory for Hearing Aids (K-IOI-HA) questionnaire were used to evaluate user satisfaction as the primary outcome. The secondary outcome measures were audiological test results and complication rates.

Results. The mean scores for ease of communication (61.3\% to $29.7 \%$ to $30.2 \%)$, reverberation $(62.1 \%$ to $43.1 \%$ to $37.4 \%$ ), and background noise $(63.3 \%$ to $37.7 \%$ to $34.3 \%)$ subscales of the APHAB questionnaire significantly decreased afterVSB surgery. The mean K-IOI-HA scores at 3 and 6 months after surgery were significantly higher than the mean preoperative score (18.6 to 27.2 to 28.1 ). The postoperative VSB-aided thresholds were significantly lower than the preoperative unaided and hearing aid (HA)-aided thresholds. There was no significant difference between preoperative unaided, preoperative HA-aided, and postoperative VSB-aided maximum phonetically balanced word-recognition scores. None of the 27 patients experienced a change in postoperative bone conduction pure tone average. One patient developed temporary facial palsy and two developed surgical wound infections.

Conclusion. RW vibroplasty resulted in improved satisfaction and audiological test results in patients with mixed hearing loss after mastoidectomy, and the complication rate was tolerable.

Keywords. Active Middle Ear Implant; Mixed Hearing Loss; Round Window; Vibroplasty; Vibrant Soundbridge

- Received September 8, 2020

Revised March 9, 2021

Accepted April 8, 2021

\footnotetext{
- Corresponding author: Jong Woo Chung

Department of Otorhinolaryngology-Head and Neck Surgery, Asan Medical Center, University of Ulsan College of Medicine, 88 Olympic-ro 43-gil, Songpa-gu, Seoul 05505, Korea

Tel: +82-2-3010-3718, Fax: +82-2-489-2773

E-mail: jwchung@amc.seoul.kr
}

Copyright $\odot 2022$ by Korean Society of Otorhinolaryngology-Head and Neck Surgery.

This is an open-access article distributed under the terms of the Creative Commons Attribution Non-Commercial License (https://creativecommons.org/licenses/by-nc/4.0) which permits unrestricted non-commercial use, distribution, and reproduction in any medium, provided the original work is properly cited. 


\section{INTRODUCTION}

Reconstruction of the ossicular chain is the preferred method of restoring interrupted sound conduction in chronic otitis media. In patients in whom conductive hearing loss is diagnosed or suspected, ossiculoplasty may be performed alongside tympanomastoidectomy; alternatively, after the pathology is removed using tympanomastoidectomy, ossiculoplasty may then be performed as a second surgical procedure [1,2]. Nevertheless, in some patients, hearing does not improve and conventional hearing aids (HAs) are sometimes needed [3]. However, after certain types of mastoidectomy, such as canal wall-down mastoidectomy, patients may be unable to wear or benefit from conventional HAs due to sound feedback and the occlusion effect [4]. In addition, the use of HA sometimes results in otorrhea, otalgia, and perforation of the tympanic membrane [5]. Active middle ear implants (AMEIs) provide an alternative therapeutic option for patients who cannot use conventional HAs, have severe otitis externa, or have undergone multiple failed ossiculoplasty procedures [6,7].

AMEIs are a useful treatment option for various types of hearing loss. In patients with moderate to severe sensorineural hearing loss, AMEI has been shown to be a safe therapeutic option with comparable efficacy to that of conventional HAs [8]. For patients with mixed or conductive hearing loss, AMEIs can provide stable and positive hearing outcomes throughout the course of long-term follow-up [7,9]. Although many studies have assessed outcomes after AMEI surgery in patients with mixed hearing loss, more information is needed on round window (RW) vibroplasty with respect to user satisfaction, efficacy, and safety. According to a systematic review by Ernst et al. [10], in which the Vibrant Soundbridge (VSB) was found to offer an effective alternative for patients with mixed hearing loss, only about half of the 19 papers using the VSB were prospective studies.Therefore, it is necessary to determine the effectiveness of RW vibroplasty through a prospective study using the same surgical method, and to provide information to patients based on the findings.

This prospective multicenter study aimed to obtain further

\section{H}

- Round window (RW) vibroplasty improved subjective satisfaction scores according to the Abbreviated Profile of Hearing Aid Benefit and the Korean version of the International Outcome Inventory for Hearing Aids questionnaires.

- Objective audiological test scores showed a significant improvement after RW vibroplasty in patients with mixed hearing loss after mastoidectomy.

- One case of temporary facial palsy and two cases of surgical wound infection related to surgery occurred. evidence regarding the user satisfaction, efficacy, and safety of RW vibroplasty in patients with mixed hearing loss persisting after mastoidectomy.

\section{MATERIALS AND METHODS}

\section{Subjects}

All patients were Korean aged between 20 and 80 years, and had a history of mastoidectomy surgery for the treatment of chronic otitis media with or without cholesteatoma. The pure tone average (PTA) was calculated using the $1 \mathrm{kHz}$ and $2 \mathrm{kHz}$ weighted average (the average of the thresholds at $0.5,1,1,2,2$, and $4 \mathrm{kHz}$ ). The inclusion criteria of this study were (1) bone conduction (BC) PTA of $\geq 25 \mathrm{~dB}$ HL and air-bone gap of $\geq 25 \mathrm{~dB}$ HL in the operated ear, (2) air conduction (AC) PTA of $\geq 25 \mathrm{~dB}$ HL in the non-operated ear, (3) a maximum phonetically balanced wordrecognition score (PBmax) on speech audiometry (SA) of $\geq 50 \%$ in the operated ear, (4) patients who did not obtain adequate benefit from HA or could not tolerate HA due to inflammation of the external auditory canal, and (5) patients who failed to achieve sufficient hearing improvement following conventional middle ear procedures including ossiculoplasty, stapes surgery, and tympanoplasty. Patients were excluded from the study if the anatomical structure of the temporal bone was inappropriate for RW vibroplasty: in patients with complete occlusion of RW or without enough space for RW vibroplasty..

\section{Surgical procedure: RW vibroplasty}

The RW vibroplasty was performed under general anesthesia using a retroauricular approach. All patients had already undergone mastoidectomy surgery before implantation. After identifying the RW niche, the floating mass transducer (FMT) attached to the RW coupler was positioned along the axis perpendicular to the RW membrane. If needed, the RW niche was drilled and enlarged. The FMT with an RW soft coupler was supported by cartilage to make close contact with the RW membrane. The electrode was placed in a bony groove made in the mastoid cavity and over the facial ridge and covered by bone pate or cartilage grafts. For all patients, theVSB AMEI system (MED-EL, Innsbruck, Austria) with a Samba audio processor (MED-EL) was used.

\section{Questionnaires}

The Korean translation of the Abbreviated Profile of Hearing Aid Benefit (APHAB) questionnaire and Korean version of the International Outcome Inventory for Hearing Aids (K-IOI-HA) questionnaire were used as subjective measures of efficacy and satisfaction. The Korean translations of the APHAB and K-IOI-HA were validated $[11,12]$. Patients were asked to complete these questionnaires before, and 3 and 6 months after the implantation surgery. The APHAB questionnaire consists of four subscales: ease of communication (EC), reverberation (RV), back- 
ground noise (BN), and aversiveness (AV). The preoperative and postoperative scores on each of these four subscales were compared to evaluate user satisfaction. The K-IOI-HA questionnaire was completed before implant surgery, and 3 and 6 months after implant surgery by patients who used HA prior to surgery. On this questionnaire, the highest possible score is 35 points and the lowest possible score is 7 points, with higher scores reflecting greater patient satisfaction.

\section{Audiological assessment}

We also performed pure tone audiometry and SA to evaluate the patients' hearing. Pure tone audiometry thresholds for AC and $\mathrm{BC}$ were recorded both preoperatively and postoperatively. One month after implantation, theVSB system was switched on. The aided sound field threshold was tested at 1,3, and 6 months postoperatively with the subject seated at a distance of $1 \mathrm{~m}$ and an angle of $45^{\circ}$ away from the speaker in an audiometric test booth. At all three postoperative time points, SA was also performed with the aid of an external audio processor, and functional gain was assessed using a warble tone.

\section{Statistical analysis}

All statistical analyses were performed using IBM SPSS ver. 22 (IBM Corp., Armonk, NY, USA). The Kruskal-Wallis test with post-hoc by Bonferroni's method and Mann-Whitney test were used for statistical comparisons. All data are presented as the mean \pm standard deviation. A $P$-value $<0.05$ was considered statistically significant.

\section{Ethical considerations}

This study was approved by the Institutional Review Board of each participating hospital, and written informed consent was obtained from the patients after a full explanation of the study. This study adhered to the tenets of the Declaration of Helsinki. All processes of this study were monitored by the Academic Research Office of Clinical Trial Center at Asan Medical Center.The study protocol was registered in the Clinical Research Information Service (CRIS, KCT0003143, http://cris.nih.go.kr)

IRB approval numbers of each participating hospital are follows: 03-2018-011, 4-2018-0577, 2018-0903, DAUHIRB 18-149, B-1806/477-005, CNUH 2018-169, AJIRB-DEV-DE3-18-199, SCHUH 2018-07-020, SCMC 2018-07-007, SMC 2018-06-127, D-1808-077-965, 2018-07-003, KC18DEDI0487, SCHBC 201901-002, and 2019-01-020.

\section{RESULTS}

\section{Patients}

This prospective, multicenter, single-subject repeated-measures study enrolled patients between October 2018 and April 2020. Twenty-seven patients (11 men and 16 women) were enrolled from 15 sites in Korea. Their age at the time of implantation surgery ranged from 28 to 76 years (mean, $58.7 \pm 10.24$ years). All patients had a history of previous mastoidectomy; the mean number of prior ear operations was 1.52. Eight operations were performed on the right ears, while the other 19 were performed on the left ears. Twenty-one out of 27 patients underwent canal walldown mastoidectomy and six patients underwent canal wall-up mastoidectomy. The incus was missing in all patients, the stapes had an intact suprastructure in 20 patients and seven patients had no suprastructure of the stapes. Patients' demographic characteristics are presented in Table 1 .

\section{Questionnaires}

Regarding the APHAB questionnaire, the mean preoperative score on the EC subscale was $61.3 \% \pm 26.0 \%$, while the mean postoperative score was $29.7 \% \pm 23.7 \%$ at 3 months after implantation surgery and $30.2 \% \pm 23.9 \%$ at 6 months after surgery. The mean score on the RV subscale was $62.1 \% \pm 22.7 \%$ preoperatively, $43.1 \% \pm 20.2 \%$ at 3 months after surgery and $37.4 \% \pm 21.5 \%$ at 6 months after surgery. The mean BN scores were $63.3 \% \pm 22.7 \%, 37.7 \% \pm 17.3 \%$, and $34.3 \% \pm 21.4 \%$ at the preoperative, 3-month postoperative, and 6-month postoperative evaluations, respectively. For the EC, RV, and BN subscales, the preoperative score was significantly higher than both the 3-month and 6-month postoperative scores, but there was no significant difference between the postoperative scores at the 3- and 6-month time points. The mean AV score was $38.1 \% \pm$ $20.2 \%$ preoperatively, $40.8 \% \pm 24.8 \%$ at 3 months after surgery, and $37.1 \% \pm 23.8 \%$ at 6 months after surgery. There was no significant difference in the mean $\mathrm{AV}$ score among the three evaluation time points $(P=0.882)$ (Fig. 1 ).

On the K-IOI-HA questionnaire, the mean preoperative score was $18.6 \pm 7.8$, the 3 -month postoperative score was $27.2 \pm 4.2$, and the 6-month postoperative score was $28.1 \pm 4.9$ in patients who used an HA prior to surgery $(\mathrm{n}=16)$. The mean preoperative score was significantly lower than the 3-month $(P<0.001)$ and the 6 -month postoperative scores $(P<0.001)$. However, there was no significant difference between the mean scores at 3 and 6 months postoperatively ( $P=0.893)$ (Fig. 2).

\section{Audiological test}

The mean preoperative BC threshold was $40.8 \pm 11.9 \mathrm{~dB} \mathrm{HL}$, the mean preoperative $\mathrm{AC}$ threshold was $75.0 \pm 14.6 \mathrm{~dB} \mathrm{HL}$, and the mean preoperative air-bone gap was $34.0 \pm 8.7 \mathrm{~dB}$ HL. The mean postoperative $\mathrm{BC}$ and $\mathrm{AC}$ thresholds were $43.4 \pm 12.0 \mathrm{~dB}$ $\mathrm{HL}$ and $80.2 \pm 15.0 \mathrm{~dB} \mathrm{HL}$, respectively. There was no significant difference between the mean preoperative and postoperative values for both the $\mathrm{BC}$ and $\mathrm{AC}$ thresholds (Fig. 3).

Preoperative pure tone audiometry thresholds and postoperative VSB-aided thresholds according to frequency are shown in Table 2. For all assessed frequencies from $250 \mathrm{~Hz}$ to $4 \mathrm{kHz}$, there was a significant difference between the preoperative pure tone 
Table 1. Patient demographics and characteristics

\begin{tabular}{|c|c|c|c|c|c|c|c|}
\hline \multirow{2}{*}{ Patient No. } & \multirow{2}{*}{ Sex } & \multirow{2}{*}{ History of HA } & \multirow{2}{*}{$\begin{array}{l}\text { Age at RW } \\
\text { vibroplasty }\end{array}$} & \multirow{2}{*}{ Surgery ear } & \multicolumn{3}{|c|}{ Previous ear surgery } \\
\hline & & & & & Diagnosis & Type of mastoidectomy & Ossiculoplasty \\
\hline 1 & M & No & 52 & Right & Chole & Down & 1 \\
\hline 2 & $\mathrm{~F}$ & Yes & 54 & Right & $\mathrm{COM}$ & Down & 1 \\
\hline 3 & $\mathrm{~F}$ & Yes & 69 & Left & $\mathrm{COM}$ & Down & 1 \\
\hline 4 & M & Yes & 56 & Right & Chole & Up & 1 \\
\hline 5 & $\mathrm{M}$ & Yes & 59 & Left & $\mathrm{COM}$ & Down & 1 \\
\hline 6 & $M$ & Yes & 65 & Left & Chole & Down & 1 \\
\hline 7 & M & Yes & 50 & Left & $\mathrm{COM}$ & Down & 1 \\
\hline 8 & $\mathrm{~F}$ & No & 70 & Left & $\mathrm{COM}$ & Down & 1 \\
\hline 9 & $\mathrm{~F}$ & Yes & 60 & Left & $\mathrm{COM}$ & Down & 2 \\
\hline 10 & $\mathrm{~F}$ & Yes & 63 & Right & Chole & Down & 1 \\
\hline 11 & $M$ & No & 47 & Right & $\mathrm{COM}$ & Down & 1 \\
\hline 12 & $\mathrm{~F}$ & Yes & 65 & Left & $\mathrm{COM}$ & Down & 2 \\
\hline 13 & $\mathrm{~F}$ & No & 28 & Left & $\mathrm{COM}$ & Up & 3 \\
\hline 14 & $\mathrm{~F}$ & No & 67 & Left & $\mathrm{COM}$ & Up & 1 \\
\hline 15 & $\mathrm{~F}$ & No & 58 & Left & $\mathrm{COM}$ & Down & 1 \\
\hline 16 & $\mathrm{~F}$ & No & 48 & Left & Chole & Down & 2 \\
\hline 17 & $\mathrm{~F}$ & Yes & 76 & Right & Chole & Down & 3 \\
\hline 18 & $\mathrm{~F}$ & Yes & 53 & Left & Chole & Down & 2 \\
\hline 19 & $\mathrm{M}$ & Yes & 61 & Left & Chole & Up & 1 \\
\hline 20 & $\mathrm{~F}$ & No & 56 & Left & $\mathrm{COM}$ & Down & 3 \\
\hline 21 & $M$ & Yes & 57 & Right & $\mathrm{COM}$ & Down & 1 \\
\hline 22 & $M$ & No & 47 & Left & $\mathrm{COM}$ & Up & 1 \\
\hline 23 & $\mathrm{~F}$ & No & 72 & Left & $\mathrm{COM}$ & Down & 2 \\
\hline 24 & $\mathrm{~F}$ & No & 62 & Left & $\mathrm{COM}$ & Down & 1 \\
\hline 25 & $\mathrm{~F}$ & Yes & 58 & Left & $\mathrm{COM}$ & Up & 2 \\
\hline 26 & $M$ & Yes & 56 & Left & $\mathrm{COM}$ & Down & 2 \\
\hline 27 & $M$ & Yes & 76 & Right & $\mathrm{COM}$ & Down & 2 \\
\hline
\end{tabular}

HA, hearing aids; RW, round window; Chole, chronic otitis media with cholesteatoma; COM, chronic otitis media without cholesteatoma; Down, canal walldown mastoidectomy; Up, canal wall-up mastoidectomy.
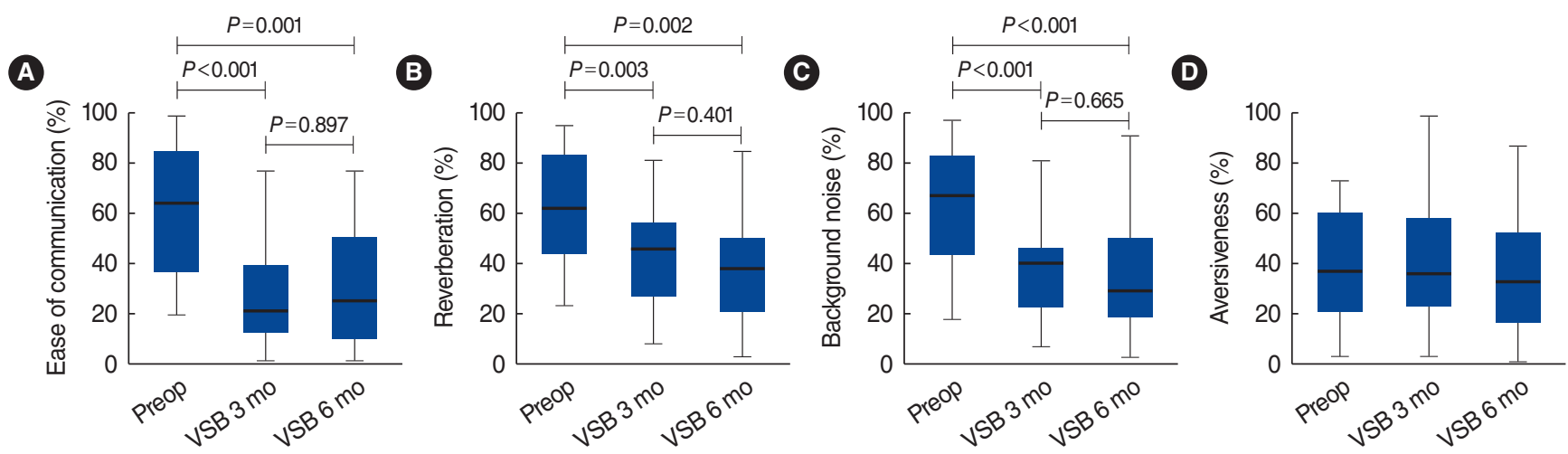

Fig. 1. Scores on the Korean translation of the Abbreviated Profile of Hearing Aid Benefit questionnaire, assessed preoperatively and at 3 and 6 months postoperatively. (A) Ease of communication subscale. (B) Reverberation subscale. (C) Background noise subscale. (D) Aversiveness subscale. Preop, preoperative; VSB, Vibrant Soundbridge; VSB 3 mo, VSB-aided thresholds at 3 months after surgery; VSB 6 mo, VSBaided thresholds at 6 months after surgery.

audiometry threshold and postoperative VSB-aided thresholds, while there were no significant differences between the VSBaided thresholds measured 1, 3, and 6 months postoperatively
(Table 2, Fig. 4A). Comparisons between preoperative HA-aided thresholds and postoperative VSB-aided thresholds revealed significant differences at $2 \mathrm{kHz}$, while there were no significant dif- 


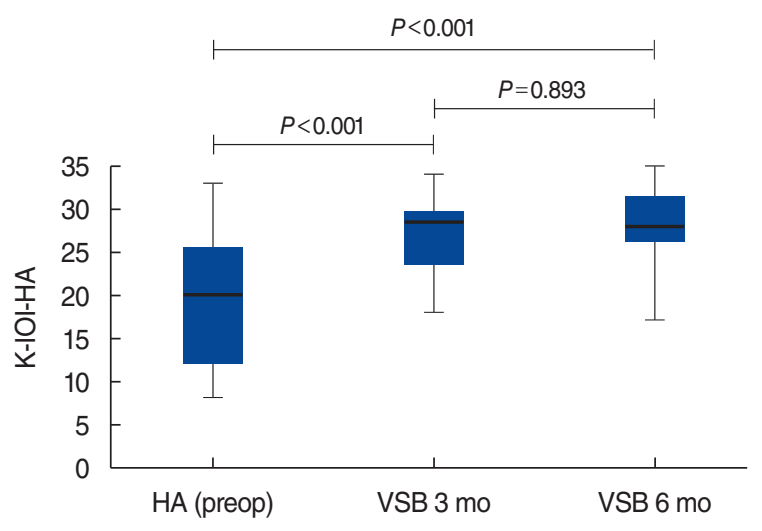

Fig. 2. Scores on the Korean version of the International Outcome Inventory for Hearing Aids (K-IOI-HA) questionnaire assessed at three different time points: preoperatively and at 3 and 6 months postoperatively. The $\mathrm{K}-\mathrm{IOI}-\mathrm{HA}$ questionnaire was completed before and 3 and 6 months after round window (RW) vibroplasty by 16 patients who used hearing aids before RW vibroplasty. HA, hearing aid; HA (preop), preoperative HA-aided thresholds; VSB, Vibrant Soundbridge; VSB 3 mo, VSB-aided thresholds at 3 months after surgery; VSB 6 mo, VSB-aided thresholds at 6 months after surgery.

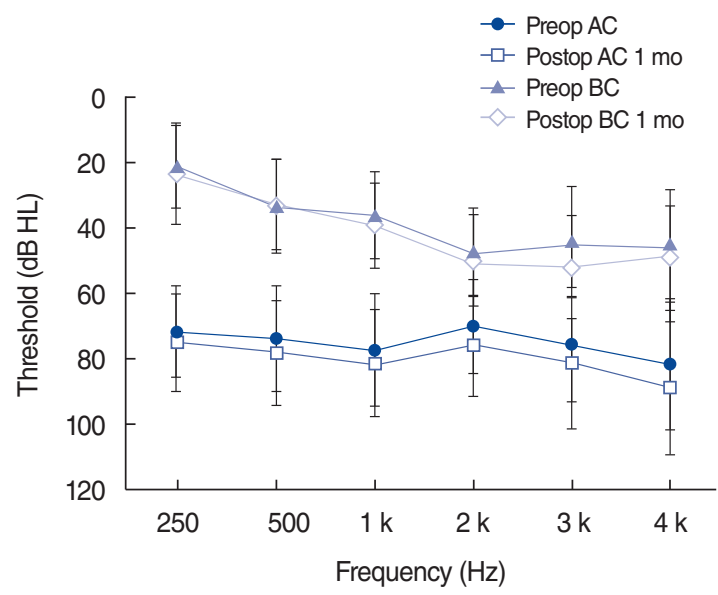

Fig. 3. Pure tone average measured preoperatively and 1 month postoperatively. There was no significant difference between mean preoperative (Preop BC) and postoperative bone conduction thresholds (Postop BC $1 \mathrm{mo})(P=0.444)$. A comparison between preoperative (Preop $\mathrm{AC}$ ) and 1-month postoperative air conduction thresholds (Postop AC $1 \mathrm{mo}$ ) revealed no significant difference $(P=0.232$ ). $\mathrm{AC}$, air conduction; $\mathrm{BC}$, bone conduction.

Table 2. Comparison between the preoperative pure tone audiometry threshold and VSB-aided thresholds at different frequencies $(\mathrm{n}=27$ )

\begin{tabular}{|c|c|c|c|c|c|}
\hline Frequency $(\mathrm{Hz})$ & Preop PT (dB HL) & VSB 1 mo (dB HL) & VSB 3 mo (dB HL) & VSB 6 mo (dB HL) & $P$-value \\
\hline 250 & $71.7 \pm 14.0$ & $53.7 \pm 15.4$ & $55.0 \pm 14.0$ & $51.5 \pm 19.6$ & $<0.001$ \\
\hline 500 & $73.7 \pm 16.3$ & $50.2 \pm 15.9$ & $46.9 \pm 14.9$ & $46.7 \pm 16.2$ & $<0.001$ \\
\hline 1,000 & $77.2 \pm 17.3$ & $39.1 \pm 11.6$ & $38.1 \pm 9.1$ & $36.5 \pm 11.0$ & $<0.001$ \\
\hline 2,000 & $70.0 \pm 14.6$ & $35.6 \pm 9.5$ & $33.3 \pm 7.7$ & $34.8 \pm 10.9$ & $<0.001$ \\
\hline 3,000 & $75.6 \pm 17.4$ & $48.1 \pm 15.7$ & $44.1 \pm 15.1$ & $42.2 \pm 14.8$ & $<0.001$ \\
\hline 4,000 & $81.9 \pm 19.5$ & $62.0 \pm 17.9$ & $54.3 \pm 16.3$ & $50.6 \pm 15.1$ & $<0.001$ \\
\hline
\end{tabular}

Values are presented as mean \pm standard deviation.

VSB, Vibrant Soundbridge; Preop PT, preoperative pure tone audiometry threshold; VSB 1 mo, VSB-aided thresholds at 1 month after surgery; VSB 3 mo, VSB-aided thresholds at 3 months after surgery; VSB 6 mo, VSB-aided thresholds at 6 months after surgery.
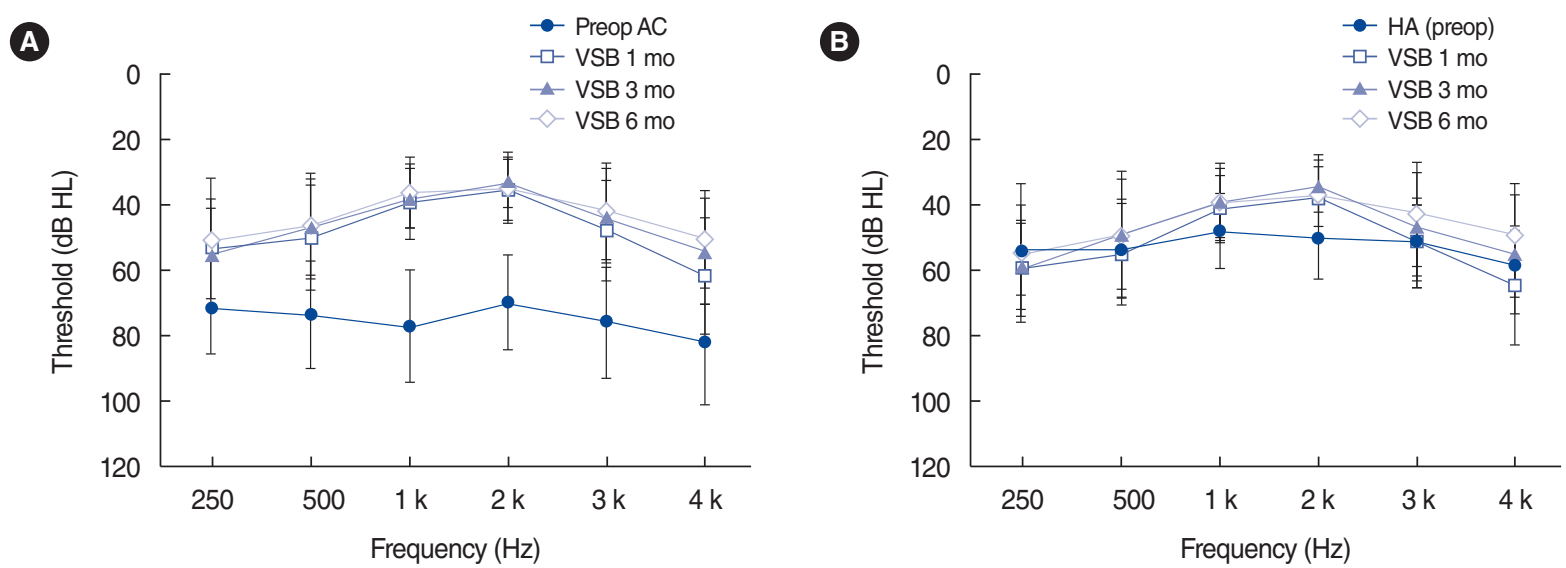

Fig. 4. Mean sound field thresholds for ears treated with round window vibroplasty, assessed using warble tones at frequencies between 250 $\mathrm{Hz}$ and $4 \mathrm{k} \mathrm{Hz}$. (A) Comparison between preoperative unaided thresholds and postoperative VSB-aided thresholds $(n=27)$. (B) Comparison between preoperative HA-aided thresholds and postoperative VSB-aided thresholds $(n=16)$. AC, air conduction; Preop AC, preoperative unaided thresholds; VSB, Vibrant Soundbridge; VSB 1 mo, VSB-aided thresholds at 1 month after surgery; VSB 3 mo, VSB-aided thresholds at 3 months after surgery; VSB 6 mo, VSB-aided thresholds at 6 months after surgery; HA, hearing aids; HA (preop), preoperative HA-aided thresholds. 
Table 3. Comparison between the HA-aided threshold and VSB-aided thresholds at different frequencies $(n=16)$

\begin{tabular}{lccccc}
\hline Frequency $(\mathrm{Hz})$ & Preop HA $(\mathrm{dB} \mathrm{HL})$ & VSB 1 mo $(\mathrm{dB} \mathrm{HL})$ & VSB 3 mo $(\mathrm{dB} \mathrm{HL})$ & VSB 6 mo $(\mathrm{dB} \mathrm{HL})$ & $P$-value \\
\hline 250 & $54.0 \pm 13.8$ & $59.4 \pm 14.8$ & $58.8 \pm 13.1$ & $54.7 \pm 21.3$ & 0.714 \\
500 & $53.3 \pm 15.0$ & $55.0 \pm 15.6$ & $49.1 \pm 16.7$ & $49.4 \pm 19.4$ & $39.4 \pm 12.1$ \\
1,000 & $48.0 \pm 11.6$ & $40.9 \pm 9.9$ & $39.4 \pm 10.5$ & $36.9 \pm 12.2$ & 0.692 \\
2,000 & $50.0 \pm 12.7$ & $37.5 \pm 9.1$ & $34.4 \pm 8.1$ & $42.8 \pm 15.9$ & 0.002 \\
3,000 & $51.0 \pm 10.9$ & $51.3 \pm 13.6$ & $46.6 \pm 16.4$ & $49.1 \pm 15.6$ \\
4,000 & $57.9 \pm 10.3$ & $64.4 \pm 18.2$ & $55.0 \pm 18.2$ & 0.307 \\
\hline
\end{tabular}

Values are presented as mean \pm standard deviation.

HA, hearing aids; VSB, Vibrant Soundbridge-aided threshold; Preop HA, preoperative hearing aid-aided threshold; VSB 1 mo, VSB-aided thresholds at 1 month after surgery; VSB 3 mo, VSB-aided thresholds at 3 months after surgery; VSB 6 mo, VSB-aided thresholds at 6 months after surgery.

ferences between theVSB-aided thresholds measured at the first, third, and sixth months postoperatively (Table 3, Fig. 4B).

The speech reception threshold (SRT) and PBmax were measured before and after the implantation surgery, and the mean preoperative and postoperative values were compared. The mean preoperative SRT was $71.9 \pm 13.7 \mathrm{~dB} \mathrm{HL}$, and the mean postoperative SRT was $73.9 \pm 13.7 \mathrm{~dB} \mathrm{HL}, 73.8 \pm 13.6 \mathrm{~dB} \mathrm{HL}$, and $73.3 \pm 13.9 \mathrm{~dB}$ HL at 1,3 , and 6 months after surgery, respectively. There was no significant difference between the mean SRT values measured at different time points $(P=0.941)$. The mean preoperative HA-aided SRT was $50.3 \pm 12.4 \mathrm{~dB}$ HL. The mean postoperative VSB-aided SRTs were 40.4 $\pm 13.0 \mathrm{~dB}$ HL, 37.9 \pm $12.8 \mathrm{~dB} \mathrm{HL}$, and $36.3 \pm 16.6 \mathrm{~dB} \mathrm{HL}$ at 1,3 , and 6 months after surgery, respectively. The mean postoperative VSB-aided SRT at 6 months after surgery was significantly lower than the mean preoperative unaided SRT $(P<0.001)$ and mean preoperative HA-aided SRT $(P=0.004)$. The mean preoperative PBmax was $79.6 \% \pm 15.0 \%$, and the mean preoperative HA-aided PBmax was $75.2 \% \pm 19.1 \%$. The mean postoperative VSB-aided PBmax was $75.3 \% \pm 17.4 \%, 75.7 \% \pm 20.6 \%$, and $80.3 \% \pm 17.6 \%$ at 1 , 3 , and 6 months after surgery, respectively. No significant difference was found when comparing the mean preoperative unaided PBmax, preoperative HA-aided PBmax, and postoperative VSBaided PBmax $(P=0.610)$.

\section{Surgical complications}

Among the 27 patients, one case of facial palsy and two cases of surgical wound infection occurred in relation to RW vibroplasty. Facial paralysis with House-Brackmann grade II occurred 3 days after surgery and the patient fully recovered after conservative treatment. Regarding the cases of surgical wound infection, one of the patients recovered with the aid of medication, but the other patient's infection did not resolve with conservative treatment including the administration of systemic antibiotics and surgical wound dressing. Five months after RW vibroplasty, the patient underwent local flap surgery to cover the implanted device that had been exposed to the infection.

\section{DISCUSSION}

The present study evaluated the satisfaction, efficacy, and safety of RW vibroplasty in a homogeneous patient group with persistent mixed hearing loss after mastoidectomy for chronic otitis media with or without cholesteatoma.

The primary endpoint of this study was subjective satisfaction, which was evaluated using the APHAB and K-IOI-HA questionnaires. The high subjective satisfaction with VSBs reflected in the APHAB questionnaire scores is in accordance with results showing good postoperative hearing threshold levels and SRT values. However, there was no significant difference in the AV subscale scores measured before and after RW vibroplasty. The AV score for some patients improved after surgery, but for others, the score deteriorated. Similar results were revealed in another study evaluating subjective satisfaction following VSB surgery [13]. In a study on the assessment of the benefits of conventional HAs, significant increases in the $\mathrm{AV}$ subscale scores were observed in the aided condition relative to that in the unaided condition [14]. We assumed that as the hearing threshold decreased after surgery, the amount of external sound perceived increased, and this noise made some patients feel uncomfortable. The K-IOI-HA is the Korean version of the IOI-HA questionnaire, which consists of seven questions to be answered using a 5-point rating system (a higher score reflects greater satisfaction). As in this study, some previous studies have compared IOI-HA scores obtained before and after VSB implantation and have shown that IOI-HA scores were significantly higher in patients with VSB implantation than in those with a conventional HA [7,15].

In our study, we found no significant difference between preoperative and postoperative values for unaided $\mathrm{BC}$ and $\mathrm{AC}$ thresholds at all frequencies. This indicates that residual hearing was preserved postoperatively, which suggests that the auditory function of the inner ear was not affected by RW vibroplasty. In other studies comparing preoperative unaided $\mathrm{BC}$ and $\mathrm{AC}$ thresholds with postoperative unaided $\mathrm{BC}$ and $\mathrm{AC}$ thresholds, VSB implantation also showed no significant change $[6,9,16,17]$. VSB implantation provided functional hearing gain, as well as preservation of residual hearing. 
In this study, no significant difference was found when comparing the mean preoperative unaided, preoperative HA-aided, and postoperativeVSB-aided PBmax. Multiple surgeries and longstanding inflammation may have damaged the sensorineural function involved in identifying words. The preoperative unaided mean PBmax was $80.0 \%$. This score is satisfactory for patients with mixed hearing loss who have already have a medical history of multiple ear surgeries.

Previous studies have identified a significant improvement in hearing thresholds, at frequencies from $250 \mathrm{~Hz}$ to $4 \mathrm{kHz}$, after VSB implantation $[18,19]$. Because the high frequencies where VSB has better gain than conventional HA are mostly between $1 \mathrm{kHz}$ and $3 \mathrm{kHz}$ [17], gain was evaluated between $250 \mathrm{~Hz}$ and $4 \mathrm{k} \mathrm{Hz}$ in this study. In other studies, audiological testing revealed a significant improvement between preoperative HA-aided and postoperative VSB-aided hearing thresholds $[9,16,20]$. We also identified a significant improvement in the aided threshold at frequencies from 1 to $4 \mathrm{kHz}$. This result is consistent with a previous report that the VSB is designed to provide a wide-frequency response in speech frequencies (medium and high); thus, the band that covers $1,000-2,000 \mathrm{~Hz}$ provides maximum stimulation by displacement of the FMT [21].

However, only 16 out of 27 patients had been using an HA before RW vibroplasty and the majority of patients who participated in this study were unable to wear an HA due to inflammation or a modified anatomical structure of the external auditory canal. Considering that 11 out of 27 patients were unable to use an HA, patients' satisfaction with RW vibroplasty can be interpreted as higher than what was revealed by the statistical values alone.

In addition, some previous studies showed better speech performance with the VSB than with an HA in background noise; nevertheless, no benefit of the VSB was observed in quiet situations [20,22]. It is suggested that for the EC, RV, and BN subscales of the APHAB, the postoperative scores improved significantly from the preoperative score, despite the lack of a significant difference in the PBmax.

A systematic review of the use of the VSB for treating conductive and mixed hearing loss reported an overall postoperative complication rate of $16.3 \%$ [10]. However, the reported explantation rate for AMEIs ranges from $10.17 \%$ to $18.5 \%$ in long-term follow-up studies of AMEI use in patients with mixed hearing loss $[17,23]$.The reasons for explantation included infection, electrode protrusion into the external auditory canal, and accidental removal by a physician. In a study evaluating the complication rate of VSB implantation in patients who had previously undergone canal wall-down mastoidectomy, 12 out of 21 patients experienced complications of varying severity [24]. These complications included cable extrusion (23.8\%), hardware failure (14.3\%), profound hearing loss $(9.5 \%)$, and inadequate FMT-RW coupling $(9.5 \%)$. All patients in that study had undergone an open tympanoplasty procedure several years before, and in the majority of cases $(86.7 \%)$, a minimal endaural approach was used for VSB implantation. Although that study had a longer follow-up period than the present study, we note that a conventional mastoidectomy approach was used for all patients in our study, and we observed a lower complication rate. Twenty-one of the 27 patients in this study had previously undergone canal wall-down mastoidectomy. The periosteal flap in these patients tended to be relatively thin, and they are therefore assumed to be at high risk of electrode extrusion. Long-term close monitoring is therefore required for these patients.

Insufficient data are currently available regarding whether RW vibroplasty results in damage to the inner ear in the long term through the stimulation of the RW membrane. Although some studies have reported long-term follow-up results, no data regarding progressive changes in hearing have been reported $[7,17,25]$. Because an accurate evaluation of inner ear function damage is difficult in older patients due to the effects of age-related hearing loss, it is necessary to monitor hearing in young patients who undergo RW vibroplasty over a long postoperative period in order to determine whether inner ear function is impaired.

In conclusion, this prospective multicenter study showed that RW vibroplasty could improve subjective satisfaction scores and audiological test scores in patients with mixed hearing loss after mastoidectomy. Although the postoperative follow-up period of this study was not lengthy (6 months), only three patients experienced complications: two cases resolved with conservative treatment and one patient required surgical intervention. In our study population, RW vibroplasty had a tolerable complication rate.

\section{CONFLICT OF INTEREST}

No potential conflict of interest relevant to this article was reported.

\section{ACKNOWLEDGMENTS}

The authors would like to thank the Biostatistics Collaboration Unit of Yonsei University College of Medicine for their contribution to this work and their constructive advice regarding the statistical analysis.

\section{ORCID}

$\begin{array}{ll}\text { Chan Il Song } & \text { https://orcid.org/0000-0002-2705-4100 } \\ \text { Hyong-Ho Cho } & \text { https://orcid.org/0000-0002-1331-4039 } \\ \text { Byung Yoon Choi } & \text { https://orcid.org/0000-0001-5125-2118 } \\ \text { Jae Young Choi } & \text { https://orcid.org/0000-0001-9493-3458 } \\ \text { Jin Woong Choi } & \text { https://orcid.org/0000-0003-3101-6841 } \\ \text { Yun-Hoon Choung } & \text { https://orcid.org/0000-0002-0786-1781 }\end{array}$




$\begin{array}{ll}\text { Jong Woo Chung } & \text { https://orcid.org/0000-0003-0765-9134 } \\ \text { Won-Ho Chung } & \text { https://orcid.org/0000-0002-8483-4429 } \\ \text { Sung Hwa Hong } & \text { https://orcid.org/0000-0001-6906-8925 } \\ \text { Yehree Kim } & \text { https://orcid.org/0000-0002-3056-198X } \\ \text { Byung Don Lee } & \text { https://orcid.org/0000-0002-8914-5569 } \\ \text { Il-Woo Lee } & \text { https://orcid.org/0000-0001-9561-6585 } \\ \text { Jong Dae Lee } & \text { https://orcid.org/0000-0003-2866-9841 } \\ \text { Jun Ho Lee } & \text { https://orcid.org/0000-0002-5519-3263 } \\ \text { Kyu-Yup Lee } & \text { https://orcid.org/0000-0001-7170-4847 } \\ \text { Il Joon Moon } & \text { https://orcid.org/0000-0002-3613-0734 } \\ \text { In Seok Moon } & \text { https://orcid.org/0000-0002-3951-5074 } \\ \text { Seung-Ha Oh } & \text { https://orcid.org/0000-0003-1284-5070 } \\ \text { Hong Ju Park } & \text { https://orcid.org/0000-0002-6331-8556 } \\ \text { Shi Nae Park } & \text { https://orcid.org/0000-0002-7614-9413 } \\ \text { JiWon Seo } & \text { https://orcid.org/0000-0001-7502-3723 }\end{array}$

\section{AUTHOR CONTRIBUTIONS}

Conceptualization: JYC, JWC (Jong Woo Chung). Data curation: HHC, ISM, YK. Formal analysis: IJM, HJP, SNP. Funding acquisition: SHH, SHO, WHC. Methodology: YHC, JWC (Jin Woong Choi), JWS, JHL. Project administration: BDL, IWL. Visualization: BYC, JDL. Writing-original draft: CIS, KYL. Writingreview \& editing: JWC (Jong Woo Chung), JYC.

\section{REFERENCES}

1. Cristobal F, Gomez-Ullate R, Cristobal I,Arcocha A,Arroyo R. Hearing results in the second stage of open mastoidectomy: a comparison of the different techniques. Otolaryngol Head Neck Surg. 2000 May; 122(5):748-51.

2. GalmT, MartinTP, RautV. Open and closed cavity mastoid operations: comparing early hearing results. Eur Arch Otorhinolaryngol. 2013 Jan;270(1):77-80.

3. Cox MD, Trinidade A, Russell JS, Dornhoffer JL. Long-term hearing results after ossiculoplasty. Otol Neurotol. 2017 Apr;38(4):510-5.

4. Geerse S, Bost TJ, Allagul S, deWolf MJ, Ebbens FA, van Spronsen E. Hearing and hearing rehabilitation after obliteration of troublesome mastoid cavities. Eur Arch Otorhinolaryngol. 2020 Dec;277(12): 3307-13.

5. Gluth MB, Friedman AB, Atcherson SR, Dornhoffer JL. Hearing aid tolerance after revision and obliteration of canal wall down mastoidectomy cavities. Otol Neurotol. 2013 Jun;34(4):711-4.

6. Maw J. The Vibrant Soundbridge: a global overview. Otolaryngol Clin North Am. 2019Apr;52(2):285-95.

7. Zahnert T, Mlynski R, Lowenheim H, Beutner D, Hagen R, Ernst A, et al. Long-term outcomes of vibroplasty coupler implantations to treat mixed/conductive hearing loss. Audiol Neurootol. 2018 Mar; 23(6):316-25.

8. Butler CL, Thavaneswaran P, Lee IH. Efficacy of the active middleear implant in patients with sensorineural hearing loss. J Laryngol
Otol. 2013 Jul;127 Suppl 2:S8-16.

9. Lee JM, Jung J, Moon IS, Kim SH, Choi JY. Benefits of active middle ear implants in mixed hearing loss: stapes versus round window. Laryngoscope. 2017 Jun;127(6):1435-41.

10. ErnstA,Todt I,Wagner J. Safety and effectiveness of theVibrant Soundbridge in treating conductive and mixed hearing loss: a systematic review. Laryngoscope. 2016 Jun;126(6):1451-7.

11. Chu H, Cho YS, Park SN, Byun JY, Shin JE, Han GC, et al. Standardization for a Korean adaptation of the international outcome inventory for hearing aids: study of validity and reliability. Korean J Otorhinolaryngol-Head Neck Surg. 2012 Jan;55(1): 20-5.

12. Lim HJ, Park MK, Cho YS, Han GC, Choi JW,AnYH, et al.Validation of the Korean version of the abbreviated profile of hearing aid benefit. Korean J Otorhinolaryngol-Head Neck Surg. 2017 Apr;60(4): 164-73.

13. Kumakawa K, Kanzaki S, Usami S, Iwasaki S, Yamanaka N, Doi K, et al. Multicenter clinical study of Vibrant Soundbridge in Japan: analysis of subjective questionnaires. Nihon Jibiinkoka Gakkai Kaiho. 2015 Nov;118(11):1309-18.

14. Dornhoffer JR, Meyer TA, Dubno JR, McRackan TR. Assessment of hearing aid benefit using patient-reported outcomes and audiologic measures. Audiol Neurootol. 2020 Jul;25(4):215-23.

15. Atas A, Tutar H, Gunduz B, Bayazit YA. Vibrant SoundBridge application to middle ear windows versus conventional hearing aids: a comparative study based on international outcome inventory for hearing aids. Eur Arch Otorhinolaryngol. 2014 Jan;271(1):35-40.

16. Iwasaki S, Usami SI,Takahashi H, KandaY,TonoT, Doi K, et al. Round Window application of an active middle ear implant: a comparison with hearing aid usage in Japan. Otol Neurotol. 2017 Jul;38(6): e145-51.

17. Brkic FF, Riss D, Auinger A, Zoerner B, Arnoldner C, Baumgartner $\mathrm{WD}$, et al. Long-term outcome of hearing rehabilitation with an active middle ear implant. Laryngoscope. 2019 Feb;129(2):477-81.

18. Schwab B, Salcher RB, Maier H, Kontorinis G. Oval window membrane vibroplasty for direct acoustic cochlear stimulation: treating severe mixed hearing loss in challenging middle ears. Otol Neurotol. 2012 Jul;33(5):804-9.

19. Bernardeschi D, Hoffman C, Benchaa T, Labassi S, Beliaeff M, Sterkers $\mathrm{O}$, et al. Functional results of Vibrant Soundbridge middle ear implants in conductive and mixed hearing losses. Audiol Neurootol. 2011 Sep;16(6):381-7.

20. Truy E, Philibert B,Vesson JF, Labassi S, Collet L.Vibrant Soundbridge versus conventional hearing aid in sensorineural high-frequency hearing loss: a prospective study. Otol Neurotol. 2008 Aug;29(5):684-7.

21. Labassi S, Beliaeff M, Pean V, Van de Heyning P.The Vibrant Soundbridge ${ }^{\circledR}$ middle ear implant: a historical overview. Cochlear Implants Int. 2017 Nov;18(6):314-23.

22. Khan A, Hillman T, Chen D. Vibrant Soundbridge rehabilitation of sensorineural hearing loss. Otolaryngol Clin North Am. 2014 Dec; 47(6):927-39.

23. Zwartenkot JW, Mulder JJ, Snik AF, Cremers CW, Mylanus EA.Active middle ear implantation: long-term medical and technical followup, implant survival, and complications. Otol Neurotol. 2016 Jun; 37(5):513-9.

24. Barbara M,Volpini L, Covelli E, Romeo M, Filippi C, Monini S. Complications after round window vibroplasty. Eur Arch Otorhinolaryngol. 2019 Jun;276(6):1601-5.

25. Schmuziger N, Schimmann F, aWengen D, Patscheke J, Probst R. Longterm assessment after implantation of the Vibrant Soundbridge device. Otol Neurotol. 2006 Feb;27(2):183-8. 